\title{
COMPRESSION OF THE DEEP PALMAR BRANCH OF THE ULNAR NERVE
}

\author{
Case Report and Anatomical Study
}

\author{
J. R. Hayes, R. C. Mulholland and B. T. O’Connor, Oswestry, England
}

Paralysis of the muscles supplied by the deep branch of the ulnar nerve is well recognised. The following case is reported because the findings at operation prompted a review of the anatomy of this region and a series of anatomical dissections of the area.

This study confirms that there is in all hands a ligamentous band which passes from the pisiform bone to the hook of the hamate, lying superficial to the deep branch of the ulnar nerve. This is not the pisohamate ligament, which lies deep to the nerve, and is not a superficial part of the flexor retinaculum.

The role of this fibrous band as a cause of compression of the deep branch of the ulnar nerve was suggested by Kopell and Thompson (1963). Nevertheless, the constant presence of this structure, which our dissections demonstrated, is not well recognised either in the standard anatomical texts (Quain 1836; Morris 1953; Grant 1958; Lockhart, Hamilton and Fyfe 1959; Spalteholz 1959; Zuckerman 1961; Hollinshead 1962; Cunningham 1964; Last 1966; Gray 1967 ) or by other writers on this type of peripheral entrapment neuropathy. One previous reference to this structure described it as an anomaly (Nicolle and Woolhouse 1965) and another as fibrosis of the hypothenar muscles due to trauma (Torok and Giora 1964).

\section{CASE REPORT}

A man aged forty-six complained of clumsiness of his left hand. This had come on suddenly about ten days before. The patient, who was right-handed, worked as a refrigerator service engineer. He could not recall any recent injury to the hand.

On examination the only abnormal findings were in the left hand, where there was clawing of the ring and little fingers of the type associated with ulnar nerve lesions. No sensory loss to light touch and pinprick, and no abnormality of sweating were detected. There was weakness of the muscles supplied by the ulnar nerve with the exception of the abductor digiti minimi muscle.

The patient was under observation for three months, during which the clawing and weakness gradually became worse. It was therefore decided to explore the deep branch of the ulnar nerve.

Operation and progress-At operation a ganglion filled with reddish mucoid material was found. Stretched over it were the deep and superficial branches of the ulnar nerve. The deep branch in resuming its normal course was seen to pass under a ligamentous band; it appeared to be sharply angled round the free edge of the band, as immediately proximal to this the nerve was pushed forward by the ganglion (Fig. 1). The ganglion, which appeared to be arising from the triquetro-hamate joint, was excised, and the band was divided because it seemed to be a factor in compressing the nerve.

Since the operation the patient has noticed gradual improvement in his muscle weakness, but recovery was not complete four months later.

\section{ANATOMICAI, STUDY}

In view of the above surgical findings, twenty-one hands in twelve necropsy subjects were dissected.

vol. 51 B, NO. 3, August 1969 
Exposure of the ulnar nerve on the medial side of the hand showed that in all cases the deep branch passed superficial to the piso-hamate ligament and beneath a fibrous arch which extended from the pisiform to the hook of the hamate (Fig. 2). The abductor and flexor of the little finger gained part of their origin from this arch, which blended distally and medially with the fascia overlying the abductor digiti minimi muscle. In two subjects the structure was rather attenuated and there were muscle fibres passing between the hamate and the pisiform with the ligamentous arch represented on their deep surface.

The branches supplying the hypothenar muscles always arose from the deep branch of the ulnar nerve, but the branch to the abductor muscle sometimes arose proximal and sometimes distal to the ligamentous arch.

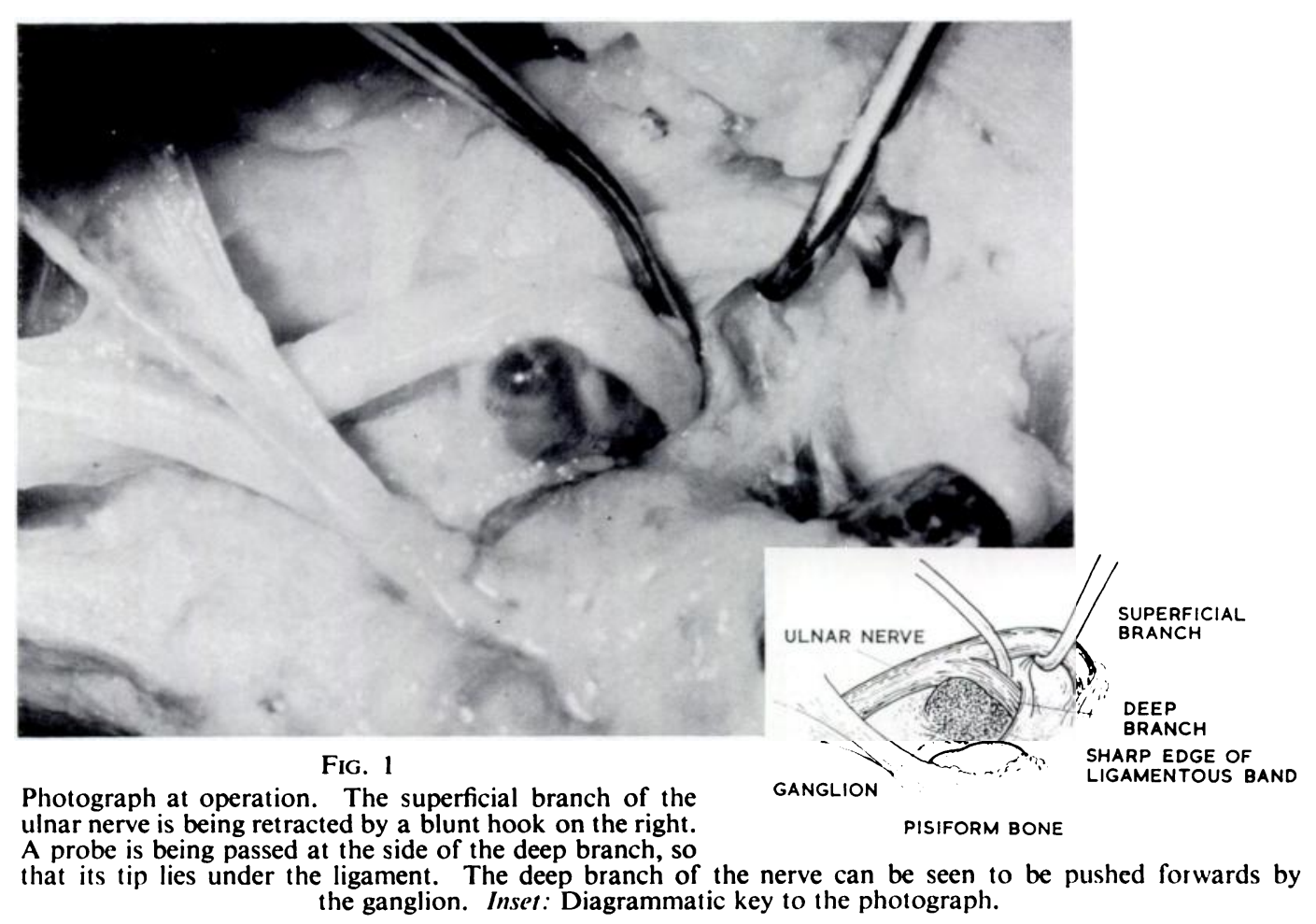

DISCUSSION

In the early descriptions of paralysis of the deep branch of the ulnar nerve it was thought to be neuritis of occupational origin (Hunt 1908, Harris 1929, Worster-Drought 1929, Russell and Whitty 1947, Wolff 1948).

Seddon (1952) then described four cases in which exploration showed the lesion to be due to a ganglion. Since Seddon's paper further cases have been reported.

There are three different patterns of presentation of paralysis of the ulnar nerve in the hand. 1) With sensory loss and weakness of all muscles supplied by the nerve (Brooks 1952; Richmond 1963; Dupont 1965);2) with no sensory.loss, but weakness of all muscles supplied by the nerve (Richmond 1963); 3) with no sensory loss, but weakness of the muscles supplied by the nerve with the exception of the hypothenar muscles (Seddon 1952):

Correlating the anatomical findings with the varying clinical presentation; complete motor and sensory loss is explained by compression of the nerve before it divides: This occurs when the ganglion is in the proximal part of the hand and compresses the nerve against the superficial part of the flexor retinaculum (syndrome de la loge de Guyon) (Merle d'Aubigné and Benassy 1956). 
More distal ganglia, however, do not compress the superficial branch. Richmond (1963) suggests that this is because ganglia in this situation enlarge distally rather than forwards. The constant presence of the ligament described above provides an alternative explanation: that, whereas the superficial branch is free to be displaced forwards, the deep branch, passing beneath the ligament, is compressed between it and the ganglion. This method of entrapment, previously suggested by Kopell and Thompson (1963), is well illustrated by the case reported here. They also suggest that some of the atrophy of the intrinsic muscles seen in rheumatoid arthritis of the hand where there is marked subluxation of the carpal bones on the radius and ulna may be caused by stretch of the deep palmar branch against this fibrous arch.

Our dissections show that the level of the origin of the nerve supplying the abductor

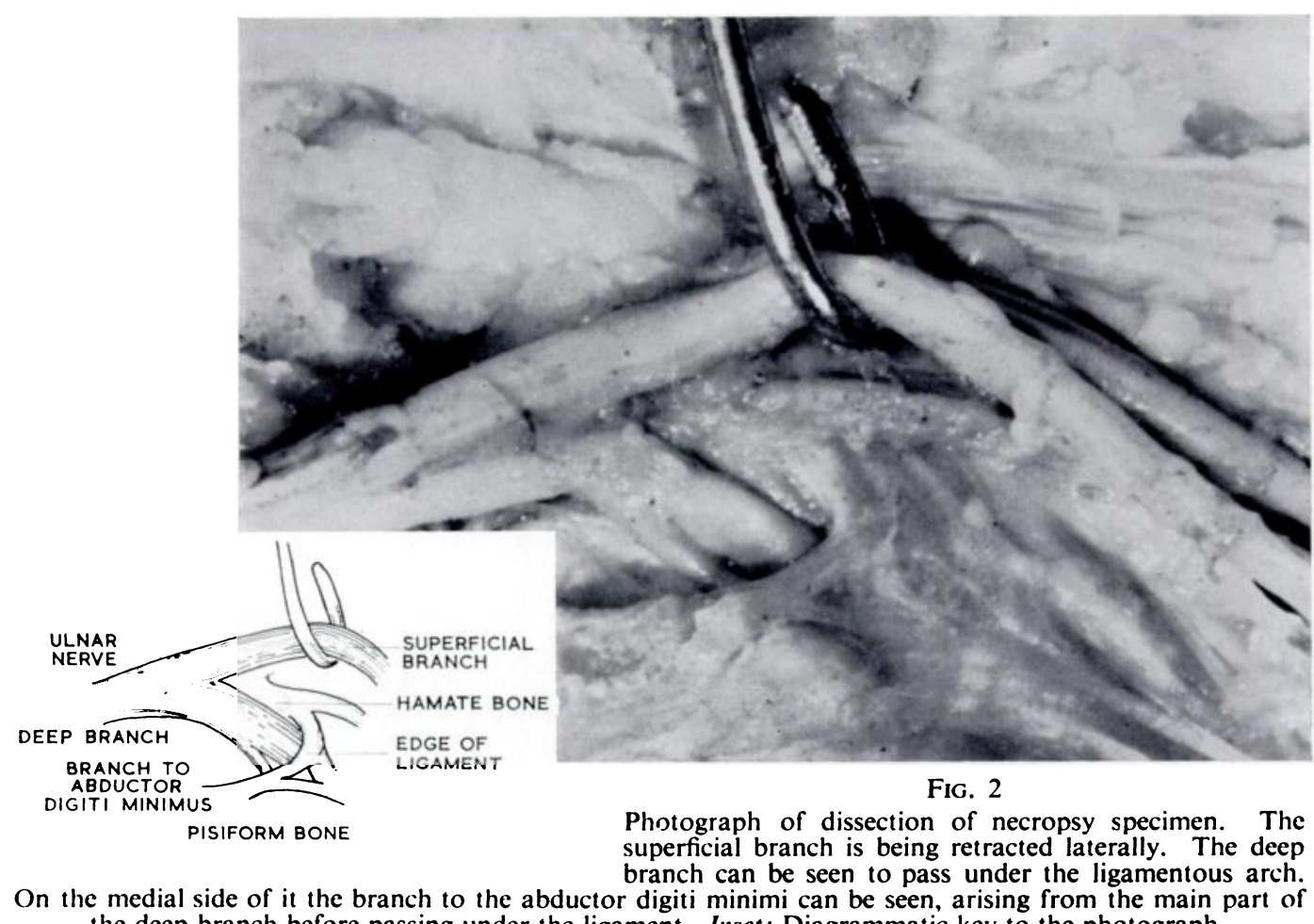

the deep branch before passing under the ligament. Inset: Diagrammatic key to the photograph.

digiti minimi muscle may be proximal or distal to the ligament. This variability combined with the possible role of the ligament in producing compression may explain the sparing of the abductor digiti minimi which is so often seen. In patients with this sparing, the nerve supply to the abductor digiti minimi probably arises proximal to the ligament and passes beneath it separately from the main branch, thus avoiding compression.

It has been evident from these dissections that many minor variations occur in the anatomy of the ulnar side of the hand. Unusual muscles have been described in this region (Lipscomb 1960) and it is of interest that both hands in one subject in this series showed a well developed accessory palmaris longus muscle. Cases of ulnar nerve compression due to an anomalous muscle have been reported (Thomas 1958; Schjelderup 1964):

\section{SUMMARY}

1: A case of compression of the deep branch of the ulnar nerve is described.

2. Anatomical evidence is presented that the reason for the special liability of the deep branch to be compressed by ganglia in this region is its relationship to a ligamentous band which 
passes from the pisiform bone to the hamate superficial to the deep branch of the ulnar nerve.

3. This band, though constant, has not been well recognised.

We would like to thank Mr D. A. Foster for the diagrams, Mr P. G. Green for the photographs and Mrs G. Davies and Miss B. Hood for secretarial assistance.

\section{REFERENCES}

Bakke, J. L., and Wolff, H. G. (1948): Occupational Pressure Neuritis of the Deep Palmar Branch of the Ulnar Nerve. Archives of Neurology and Psychiatry, 60, 549.

Brooks, D. M. (1952): Nerve Compression by Simple Ganglia. Journal of Bone and Joint Surgery, 34-B, 391.

Cunningham, D. J. (1964): Cunningham's Textbook of Anatomy. Tenth edition, edited by G. J. Romanes. London: Oxford University Press.

Dupont, C., Cloutier, G. E., Prévost, Y., and Dion, M. A. (1965): Ulnar-tunnel Syndrome at the Wrist. Journal of Bone and Joint Surgery, 47-A, 757.

Grant, J. C. B. (1958): A Method of Anatomy. Sixth edition. London: Baillière, Tindall \& Cox Ltd.

Gray, H. (1967): Gray's Anatomy, Descriptive and Applied. Thirty-fourth edition, edited by D. V. Davies. London: Longmans.

Harris, W. (1929): Occupational Pressure Neuritis of the Deep Palmar Branch of the Ulnar Nerve. British Medical Journal, $1,98$.

HollinsheAd, W. H. (1962): Textbook of Anatomy. New York: Harper \& Row.

Hunt, J. R. (1908): Occupational Neuritis of the Deep Palmar Branch of the Ulnar Nerve. Journal of Nervous and Mental Diseases, 35, 673.

Kopell, H. P., and Thompson, W. A. L. (1963): Peripheral Entrapment Neuropathies. Baltimore: The Williams \& Wilkins Company.

LAST, R. J. (1966): Anatomy, Regional and Applied. Fourth edition. London: J. \& A. Churchill Ltd.

Lipscomb, P. R. (1960): Duplication of Hypothenar Muscles Simulating Soft-tissue Tumor of the Hand. Report of a Case. Journal of Bone and Joint Surgery, 42-A, 1058.

Lockhart, R. D., Hamilton, G. F., and Fyfe, F. W. (1959): Anatomy of the Human Body. London: Faber \& Faber Limited.

Merle d'Aubigné, R., and BénAssy, J. (1956): Syndrome de la Loge de Guyon. In Chirurgie Orthopédique des Paralysies, p. 162. By R. Merle d'Aubigné, J. Bénassy and J.-O. Ramadier. Paris: Masson et Cie.

Morris, Sir H. (1953): Human Anatomy. Eleventh edition, edited by J. Parsons Schaeffer. New York: The Blakiston Company.

Nicolle, F. V., and Woolhouse, F. M. (1965): Nerve Compression Syndromes of the Upper Limb. Journal of Trauma, 5, 313.

QuaIN, J. (1836): The Muscles of the Human Body. London: Taylor \& Walton.

Richmond, D. A. (1963): Carpal Ganglion with Ulnar Nerve Compression. Journal of Bone and Joint Surgery, 45-B, 513.

Russell, W. R., and Whitty, C. W. M. (1947): Traumatic Neuritis of the Deep Palmar Branch of the Ulnar Nerve. Lancet, $1,828$.

SChJelderup, H. (1964): Aberrant Muscle in the Hand Causing Ulnar Nerve Compression. Journal of Bone and Joint Surgery, 46-B, 361.

Seddon, H. J. (1952): Carpal Ganglion as a Cause of Paralysis of the Deep Branch of the Ulnar Nerve. Journal of Bone and Joint Surgery, 34-B, 386.

Spalteholz, W. (1959): Atlas of Human Anatomy. London: Butterworth \& Co. (Publishers) Ltd.

Thомаs, C. G., Jun. (1958): Clinical Manifestations of an Accessory Palmaris Muscle. Journal of Bone and Joint Surgery, 40-A, 929.

Torok, G., and Giora, A. (1964): Ulnar Nerve Lesion in the Palm Entrapment Neuropathy of Deep Branch of Ulnar Nerve. Israel Medical Journal, 23, 121.

Worster-Drought, C. (1929): Pressure Neuritis of Deep Palmar Branch of the Ulnar Nerve. British Medical Journal, 1, 247.

Zuckerman, Sir S. (1961): A New System of Anatomy. London: Oxford University Press. 